Supporting Information to:

\title{
Tumor-targeting immune system engagers (ISErs) activate human neutrophils after binding to cancer cells
}

André J.G. Pötgens, Anne C. Conibear, Claudia Altdorf, Clarissa Hilzendeger, Christian F.W. Becker

\section{List of contents:}

\section{Methods section:}

SI p.2 Details on bead-based immune assays

SI p.2 Cytochrome c reduction assay for measuring induction of respiratory burst

SI p.3 Details on tumor-cell based immune assays

\section{Results section:}

SI p.4 Figure S1. Details on the assays measuring activation of granulocytes

SI p.6 Figure S2A. Inhibition of staining with anti-FPR-1-FITC antibody in the presence of $10 \mu \mathrm{M} \mathrm{Y}$-scaffold or Y-9

SI p.7 Figure S2B. Inhibition of Y-9 induced neutrophil activation by anti-FPR-1 antibody

SI p.8 Figure S3. Absorption of Y-9 and Yb-9 by antibody-loaded protein A beads

Estimation of the amounts binding to protein A beads

SI p.9 Figure S4. Details on the assays using ISEr-loaded protein A beads

SI p.10 Figure S5A. Neutrophil activation as a function of protein A bead amounts

SI p.11 Figure S5B. Neutrophil activation as a function of density of active ISEr loaded on antibody-coated protein A beads

SI p.12 Figure S5C. Cytochrome c reduction assay used for analyzing neutrophil activation by ISEr-coated protein A beads or their $37^{\circ} \mathrm{C}$ supernatants

SI p.13 Figure S6. Depletion of Yb-9 by streptavidin beads, activation of neutrophils by Yb-9 loaded streptavidin beads and the effect of complexing biotinylated ISErs/effector peptide with soluble streptavidin on their potencies

SI p.14 Figure S7. Forced release of Y-9 from protein A beads Estimation of the amounts released from protein A beads

SI p.15 Figure S8. Demonstration of binding of Yb-9 and B9b to cell lines

SI p.16 Figure S9. Additional data on the activation of neutrophils by tumor cells incubated with integrinbinding ISErs

SI p.17 Figure S10. Demonstration of the disappearance of cell membrane-bound Yb-9 at $37^{\circ} \mathrm{C}$ Estimation of the amount of integrin-binding ISEr bound to and released by tumor cells

SI p.18 Figure S11A. Demonstration of binding of Yb-59, Tet-Yb-59 and Yb-sc59 to PC-3 cells

SI p.19 Figure S11B: Demonstration of the rate of disappearance of PC-3 cell membrane-bound Yb-59, Tet-Yb59 or Yb-sc59 on ice or at $37^{\circ} \mathrm{C}$

SI p.20 Figure S12. Additional immune activation assays using PC-3 cells incubated with EphA2 binding ISErs or supernatants thereof

SI p.21 Figure S13. Dose effect curves showing the effects of increasing concentrations of soluble Yb-59, TetYb-59 and Yb-sc59

SI p.22 Estimation of the amount of EphA2-binding ISEr bound to and released by tumor cells 


\section{Details on bead-based immune assays}

Unless otherwise stated, $2 \mathrm{mg}$ portions of beads were washed three times with $1 \mathrm{~mL}$ of assay buffer (Hepes-buffered Hank's balanced salt solution with BSA and EDTA). Washing was done by centrifugation in Eppendorf tubes for 1 min at $10000 \mathrm{rpm}$ at room temperature (RT), removal of the supernatant and resuspension of the bead pellet in buffer by pipetting up and down. After washing the bead pellets were resuspended in $0.6 \mathrm{~mL}$ of a $44 \mu \mathrm{g} / \mathrm{mL}$ dilution of the anti-B9 antibody in assay buffer (diluted from a $220 \mu \mathrm{g} / \mathrm{mL}$ stock containing $50 \%$ glycerin, and hence still containing $10 \%$ glycerin). The bead suspensions were incubated for $1 \mathrm{~h}$ at RT and regularly mixed by vortexing and by pipetting up and down to prevent sedimentation. Next, the antibody-loaded beads were washed three times again in $1 \mathrm{~mL}$ assay buffer and then resuspended in $25 \mu \mathrm{L}$ assay buffer per portion of $2 \mathrm{mg}$ beads. The bead portions were mixed with equal volumes of a $3 \mu \mathrm{M}$ dilution of Y-9, Yb-9, bY-9 or Yb-scaffold, a $6 \mu \mathrm{M}$ dilution of B9 or B9b, mixtures of the aforementioned compounds, or with assay buffer only. Note that $2 \mathrm{mg}$ beads with a binding capacity of $16 \mu \mathrm{g}=107$ pmol IgG were incubated with 75 pmol ISEr (containing two B9 binding peptides per molecule) or 150 pmol B9 or B9b single binding peptides. Beads were incubated with the compounds for $1 \mathrm{~h}$ at RT and regularly mixed by vortexing and by pipetting up and down to prevent sedimentation. After this step, the beads were pelleted and the $50 \mu \mathrm{L}$ supernatants containing the unbound ISEr or control compound were carefully removed and stored at RT until use in the activation assay. To check the efficiency of ISEr adsorption by the beads, $25 \mu \mathrm{L}$ volumes of the original 3-6 $\mu \mathrm{M}$ dilutions were incubated with $25 \mu \mathrm{L}$ assay buffer without beads in parallel and used in the assay as a reference. The pelleted beads were washed three times with $1 \mathrm{~mL}$ assay buffer again. Finally, the bead pellets were resuspended in 50 $\mu \mathrm{L}$ of assay buffer and added to the leukocyte activation assay as soon as possible. Serial dilutions of the bead samples in assay buffer were made to allow for adding variable amounts of beads to the assay. In most experiments 0,5 mg of each bead sample was added to the leukocyte assay. For testing whether ISEr was released from beads during the immune stimulation assay, some bead aliquots were incubated in assay buffer ( $50 \mu \mathrm{l} / 0.5 \mathrm{mg}$ beads) either on ice or at $37^{\circ} \mathrm{C}$ for $20 \mathrm{~min}$ and then pelleted at $4^{\circ} \mathrm{C}$. Bead supernatants (50 $\mu \mathrm{L}$ portions) and the beads resuspended in $50 \mu \mathrm{L}$ fresh assay buffer were added to the leukocyte activation assay. Due to the high numbers of beads in the samples, the acquisition speed of the FACS Canto was kept low enough to stay below a threshold rate of 10000 events/second. If necessary, the samples were diluted with PBS to stay under this limit. In most cases, a leukocyte stopping and storage gate was defined that excluded the beads from counting and from storage in the file. At least 10000 but preferably 20 000 leukocytes were counted of each sample. In the evaluation of data, live neutrophilic granulocytes were gated and analyzed by their mean FSC and rhodamine-positivity.

\section{Cytochrome c reduction assay for measuring induction of respiratory burst}

An alternative assay for measuring respiratory burst, the cytochrome c reduction assay, was adapted from Rist et al., 1991. ${ }^{1}$ The assay was performed in 96-well plates. Each well contained crude leukocytes (250 000/200 $\mu \mathrm{L}$ ) in Hepesbuffered Hank's balanced salt solution with 0,3\% BSA (assay buffer) also containing $50 \mu \mathrm{M}$ cytochrome c (from equine heart, obtained from Signa Aldrich). Leukocytes were pre-incubated for $10 \mathrm{~min}$ at $37^{\circ} \mathrm{C}$ before the addition of the stimuli. Soluble ISErs were added in $2 \mathrm{x}$ the final concentrations (diluted in assay buffer with $100 \mu \mathrm{M}$ cytochrome c) to cells pre-incubated in $100 \mu \mathrm{L} /$ well buffer only. Beads and bead supernatants were added as $40 \mu \mathrm{l}$ volumes in assay buffer to $160 \mu \mathrm{l}$ of cells preincubated in assay buffer $+62,5 \mu \mathrm{M}$ cytochrome c (leading to identical effective stimulus concentrations as in the DHR assay in which $50 \mu \mathrm{l}$ of beads/supernatants were added to $200 \mu \mathrm{l}$ of preincubated cells). Cells with stimuli were incubated for another $20 \mathrm{~min}$ at $37^{\circ} \mathrm{C}$. The plates were cooled on ice, centrifuged $5 \mathrm{~min}$ $1500 \mathrm{rpm}$ and $100 \mu \mathrm{l}$ of supernatant was transferred from each well to a fresh plate. Cytochrome c reduction was monitored by an increase in the absorption at $550 \mathrm{~nm}$. Each condition was performed in duplicate. Each duplicate condition also had an identical control containing $10 \mu \mathrm{g} / \mathrm{ml}$ final concentration of superoxide dismutase (SOD, Sigma Aldrich), the absorbance of which was subtracted from the value of the neighboring well without SOD. Activation was expressed as the SOD inhibitable increase of E550 $\mathrm{nm}$. 


\section{Details on tumor-cell based immune assays}

Detached tumor cells were pelleted (5 min $1500 \mathrm{rpm}$ at $4^{\circ} \mathrm{C}$ ), washed once with washing buffer $(10 \mathrm{mM}$ Hepes, $\mathrm{pH}$ 7.3 in $0.9 \% \mathrm{NaCl})$ at $4^{\circ} \mathrm{C}$, and then resuspended $\left(4-5 \times 10^{6} \mathrm{cells} / \mathrm{mL}\right)$ in peptide blocking buffer (PBB): $10 \mathrm{mM}$ Hepes, $\mathrm{pH} 7.3$ in $0.9 \% \mathrm{NaCl}+5 \mathrm{mM} \mathrm{KCl}, 3 \% \mathrm{BSA}+5 \% \mathrm{FCS}$, containing also $4 \mathrm{mM} \mathrm{MnCl}_{2}$ (2x final concentration) when ISErs containing the $\mathbf{B 9}$ binder peptide were used. ISErs and control substances were prepared at $2 \mu \mathrm{M}$ (or $200 \mathrm{nM}$ for Tet-Yb-59) ( 2 x final concentrations) in PBB. Samples of 2-2.5 x $10^{6}$ cells (500 $\mu \mathrm{L}$ portions) were pipetted into FACS tubes and incubated for $10 \mathrm{~min}$ on ice before addition of 1 volume of the peptide samples (500 $\mu \mathrm{l})$. After $30 \mathrm{~min}$ incubation on ice at final ISEr concentrations of $1 \mu \mathrm{M}$ (or $100 \mathrm{nM}$ ), higher than the calculated binding affinities of these compounds (Conibear et al., 2018), cell samples were washed twice (the Y-9 ISEr family) or three times (the $\mathbf{Y}$ 59 ISEr family) with $2 \mathrm{~mL}$ washing buffer at $0^{\circ} \mathrm{C}$ and once more with $1 \mathrm{~mL}$ assay buffer at $0^{\circ} \mathrm{C}$ (see above). Cells were transferred to fresh FACS tubes on ice after the first, second and (where applicable: Y-59 family) third washing step to prevent carry-over of ISEr via tube walls. After the last washing step cells were resuspended in $125 \mu \mathrm{L}$ assay buffer of $0^{\circ} \mathrm{C}$. Cells were either added into the leukocyte activation assay directly, or were transferred to fresh Eppendorf tubes and incubated for $20 \mathrm{~min}$ on ice or at $37^{\circ} \mathrm{C}$. This extra incubation was intended to check for release of activating species from the cells. After the 20 min incubation the cells were pelleted $\left(5 \mathrm{~min} 3000 \mathrm{rpm}\right.$ at $4^{\circ} \mathrm{C}$ in an Eppendorf centrifuge). The $125 \mu \mathrm{L}$ cell supernatants were added to the leukocyte activation assay directly, and in some cases the cell pellets were again resuspended in $125 \mu \mathrm{L}$ assay buffer and added to the activation assay. 2-2.5 x $10^{6}$ ISEr-incubated tumor cells were added into the activation assays (8-10-fold the number of leukocytes in the assay). In the FACS analysis of samples containing tumor cells 100000 events were acquired, of which about $9-11 \%$ were the leukocytes of interest. 
A
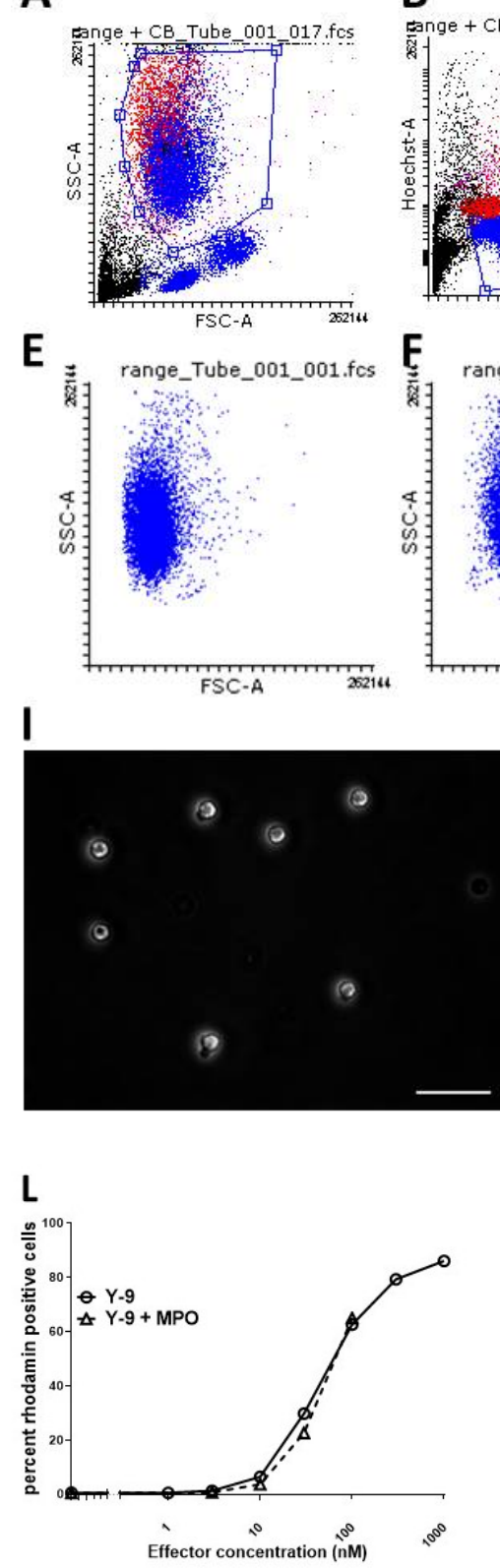

B

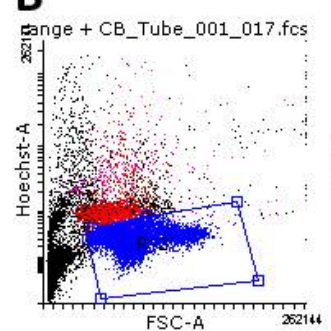

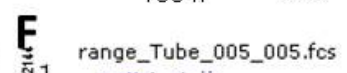

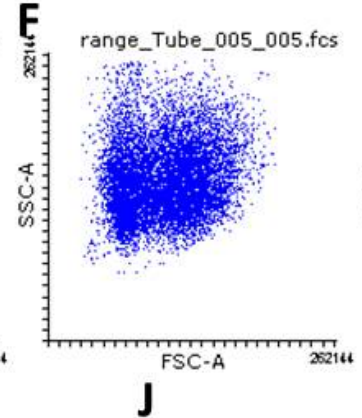

J

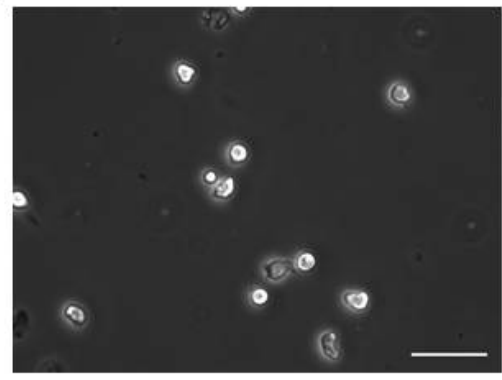

M

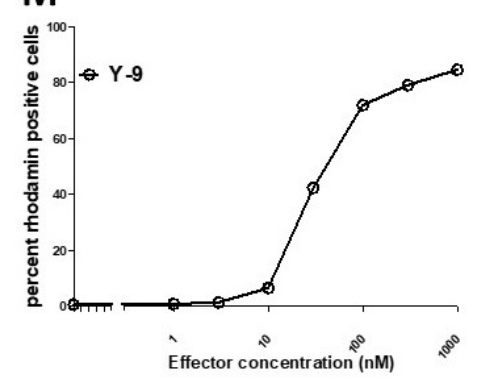

D

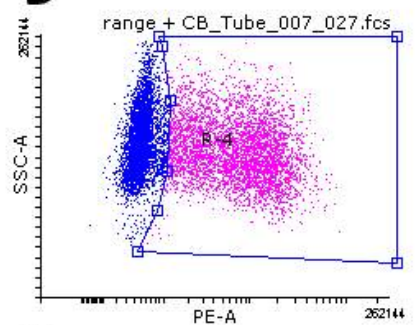

H

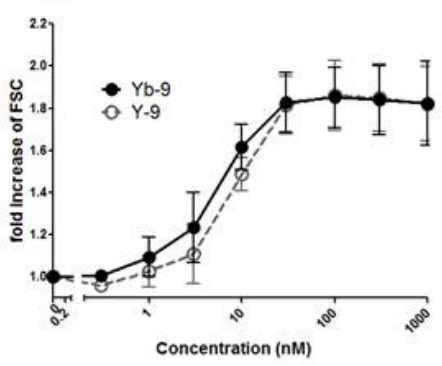

K
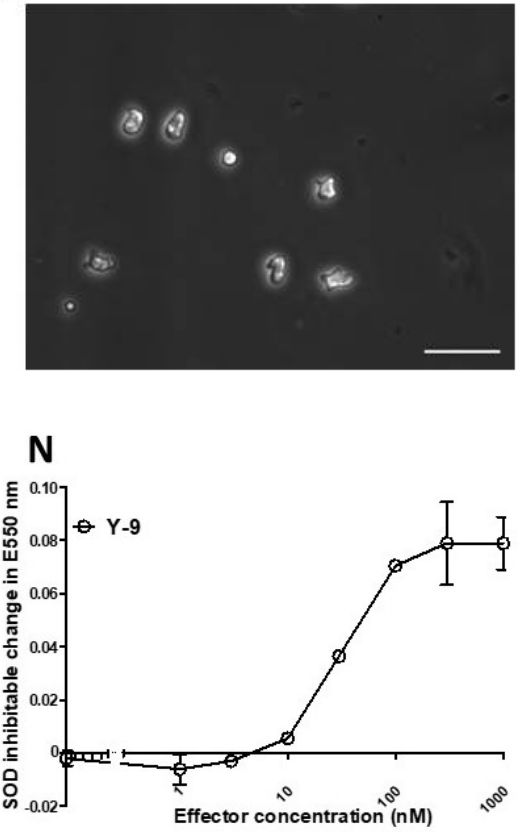

Figure S1. Details on the assays measuring activation of granulocytes. Panels A-G: Examples of FACS plots. Panels A and B show the gating of human granulocytes (unstimulated) in the FSC/SSC plot (A) and the gating of live cells as well as the exclusion of eosinophils (red, non-responsive in the activation assays, and which have a higher autofluorescence than neutrophils ${ }^{2}$ ) in the FSC/Hoechst plot (B). Panels C and D show the recognition (in region R4, pink) of neutrophilic granulocytes with activated phagocyte NADPH oxidase and which oxidize DHR into the fluorescent dye rhodamine, in a PE/SSC plot. Cells in panels C and D were incubated in the presence of cytochalasin B with no stimulus (C) or with 300 nM Yb-9 (D). Panels E-G illustrate the increase of the mean forward scatter (FSC) of neutrophils after the incubation with 0 (E), $10 \mathrm{nM}(\mathrm{F})$ or $1 \mu \mathrm{M}(\mathrm{G})$ of Y-9 in the absence of cytochalasin B. Panel $\mathrm{H}$ : Dose effect curves showing the increase of FSC of neutrophils by increasing concentrations of Y-9 and Yb-9 in the absence of cyto B. This is a compilation of the data acquired in four experiments. To compare the FSC values of four experiments, the values of the unstimulated samples were normalized to 1. Shown are the mean fold increases in FSC 
and the standard deviations of four measurements (0.3 nM was measured only twice). Panels I-K: Photomicrographs (inverted microscope (Zeiss Axiovert A1) with phase contrast, white size bars represent $50 \mu \mathrm{m}$ ) illustrating the shape change of human leukocytes (mainly neutrophils) that had been submitted to a DHR oxidation/shape change assay with increasing amounts of Yb-9 in the absence of cytochalasin B. After the assay cells were fixed in 1\% formaldehyde and put into a Neubauer chamber (0.1 mm thickness) in the presence of trypan blue (to show that the cells were alive). Cells were incubated with 0 (I, round cells), $1 \mathrm{nM}(\mathrm{J})$ and $300 \mathrm{nM}$ (K, irregular shapes) Yb-9. Panel L: Addition of exogenous myeloperoxidase (MPO; $1 \mathrm{U} / \mathrm{ml}$; obtained from Sigma Aldrich; isolated from human leukocytes) to the DHR oxidation assay does not change the sensitivity of the assay to Y-9 (performed in the absence of cytochalasin B). Panels M and N: Comparing the sensitivities of the DHR oxidation assay and the cytochrome c reduction assay (means and SDs are depicted of duplicate absorbance measurements). Both assays were performed with the same batch of $\mathbf{Y}$ 9 using leukocytes from the same donor on the same day and without cytochalasin B. 


\section{A. Staining with anti-FPR-1-FITC (colored) vs isotype control-FITC (black)}

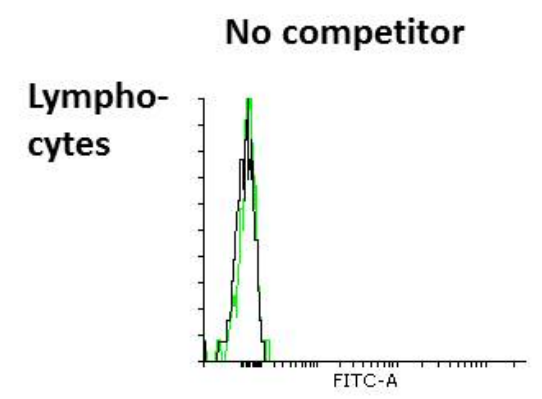

$+10 \mu \mathrm{M}$ Y-scaffold
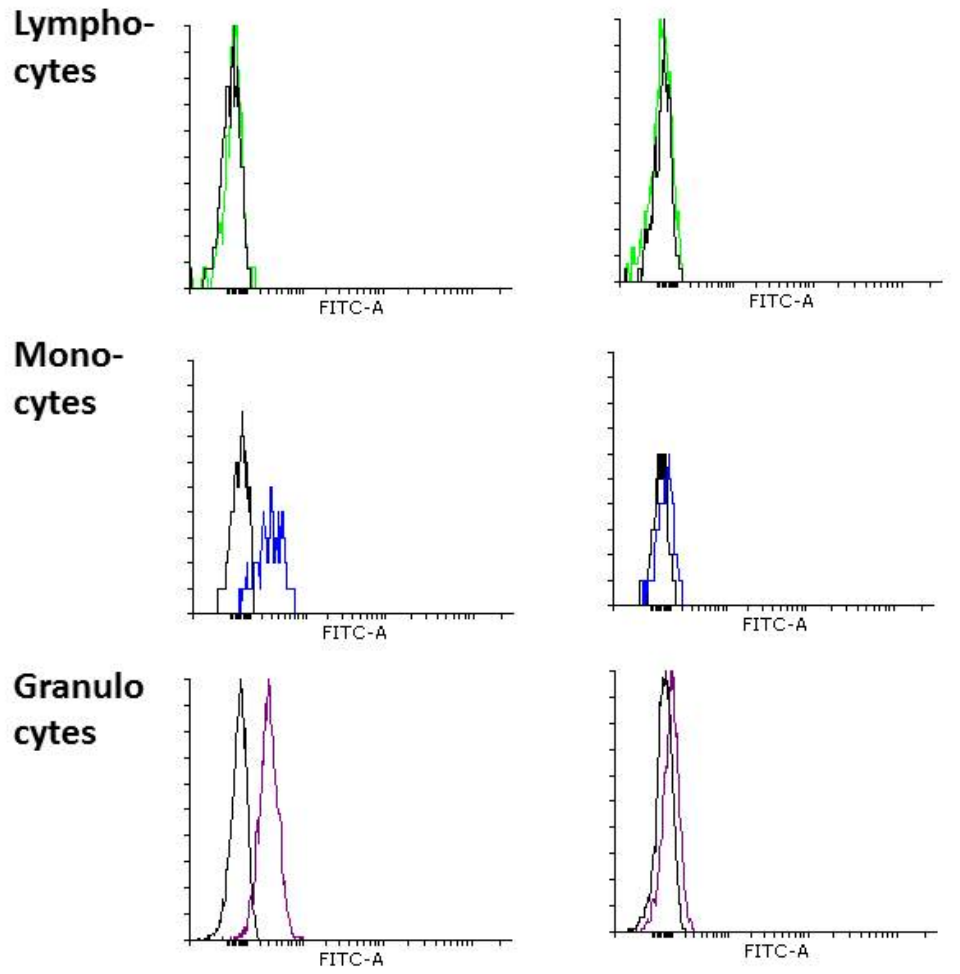
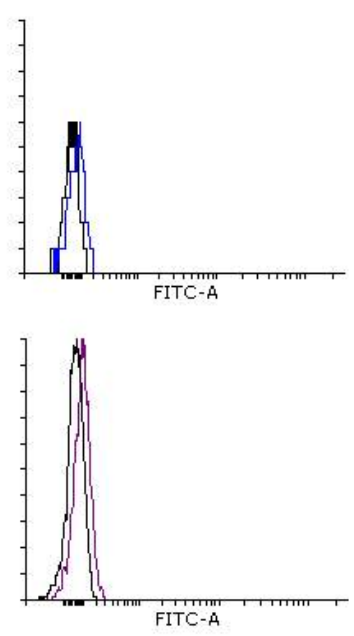

$+10 \mu \mathrm{M} \mathrm{Y}-9$
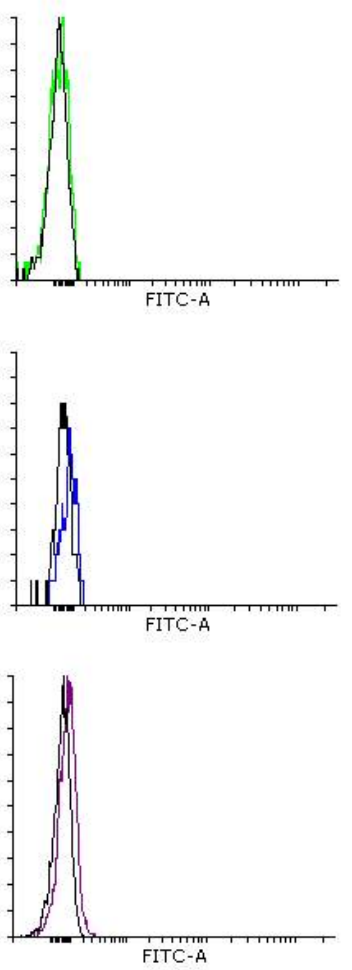

Figure S2A. Inhibition of staining with anti-FPR-1-FITC antibody in the presence of $10 \mu \mathrm{M}$ Y-scaffold or Y-9. The antibodies used and the method have been described in Brehs et al., 2018. In this case, leukocytes were first incubated for $10 \mathrm{~min}$ at $15^{\circ} \mathrm{C}$ in blocking buffer with $20 \mu \mathrm{M}$ of the indicated competitor compounds before the addition of equal volumes of the antibodies diluted 1:25 in the same blocking buffer. Staining with the antibodies was carried out for $30 \mathrm{~min}$ at $15^{\circ} \mathrm{C}$ (final dilutions 1:50 of the antibodies and final concentrations of the competitors $10 \mu \mathrm{M}$ ). Washing and analysis by flow cytometry were performed as described before (Brehs et al, 2018). Live leukocytes were subdivided into lymphocytes, monocytes and granulocytes based upon FSC/SSC plots and subpopulations were analyzed for FITC fluorescence in histogram overlays.

FPR-1 signals on monocytes and granulocytes were clearly inhibited by $10 \mathrm{uM}$ of both Y-scaffold and Y9. 


\section{B. Granulocyte activation by Y-9 with or without anti-FPR-1 antibody}

\section{Granulocyte shape change}

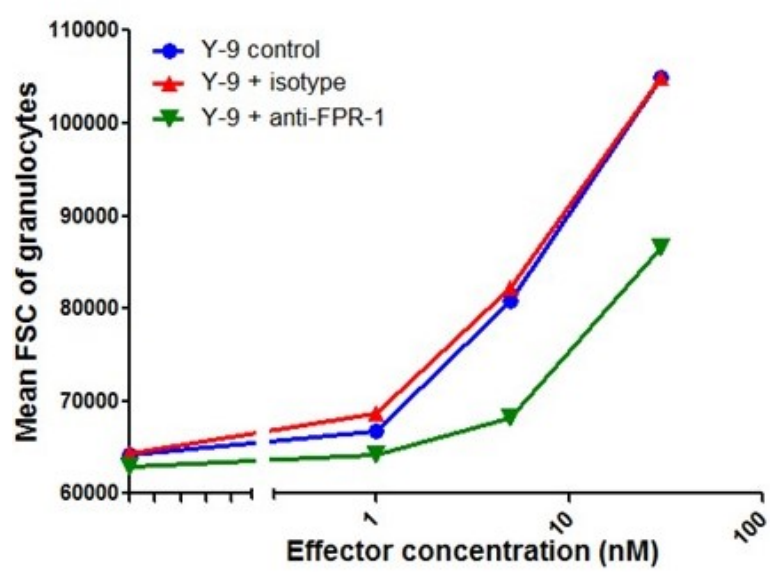

\section{Respiratory burst}

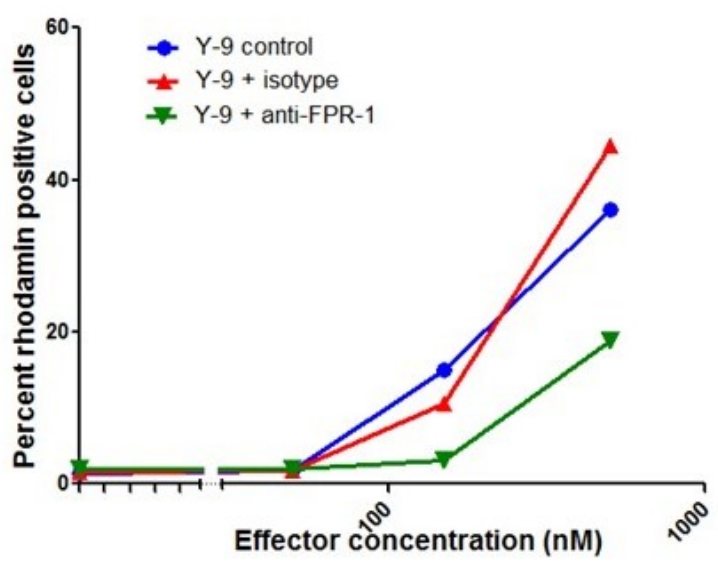

Figure S2B. Inhibition of Y-9 induced neutrophil activation by anti-FPR-1 antibody. 1: Granulocyte activation (FSC changes) in the absence of cytochalasin B; 2: DHR oxidation in the presence of cytochalasin B. Varying concentrations of Y-9 were added in the presence or absence of $5 \mu \mathrm{g} / \mathrm{mL}$ unlabeled anti-FPR-1 antibody (Mouse IgG2a, clone 350418, R\&D Systems) or isotype control antibody (Mouse IgG2a, clone 20102, R\&D Systems), both being intact IgGs. The antibodies were first added at $2 \mathrm{x}$ the final concentrations to the leukocytes in assay buffer and incubated with the cells for $10 \mathrm{~min}$ at $15^{\circ} \mathrm{C}$ prior to transferring the suspensions to $37^{\circ} \mathrm{C}$ and the addition of an equal volume of the $\mathbf{Y}-\mathbf{9}$ dilutions in the same assay buffer at $2 \mathrm{x}$ the final concentrations.

In both assay conditions the anti-FPR-1 antibody, but not the isotype control, inhibited the potency of Y-9 to activate human granulocytes as witnessed by the right-shift of the green curves. The incomplete inhibition of the activation by Y-9 in the presence of anti-FPR-1 antibody may have been caused by an insufficient amount of IgG. An alternative explanation could be the activation of neutrophils by the antibody through Fc receptors, although in the absence of $\mathbf{Y}$ 9 no activation of neutrophils by the antibodies was observed (Effector concentration $=0$ at the $\mathrm{Y}$-axes). 

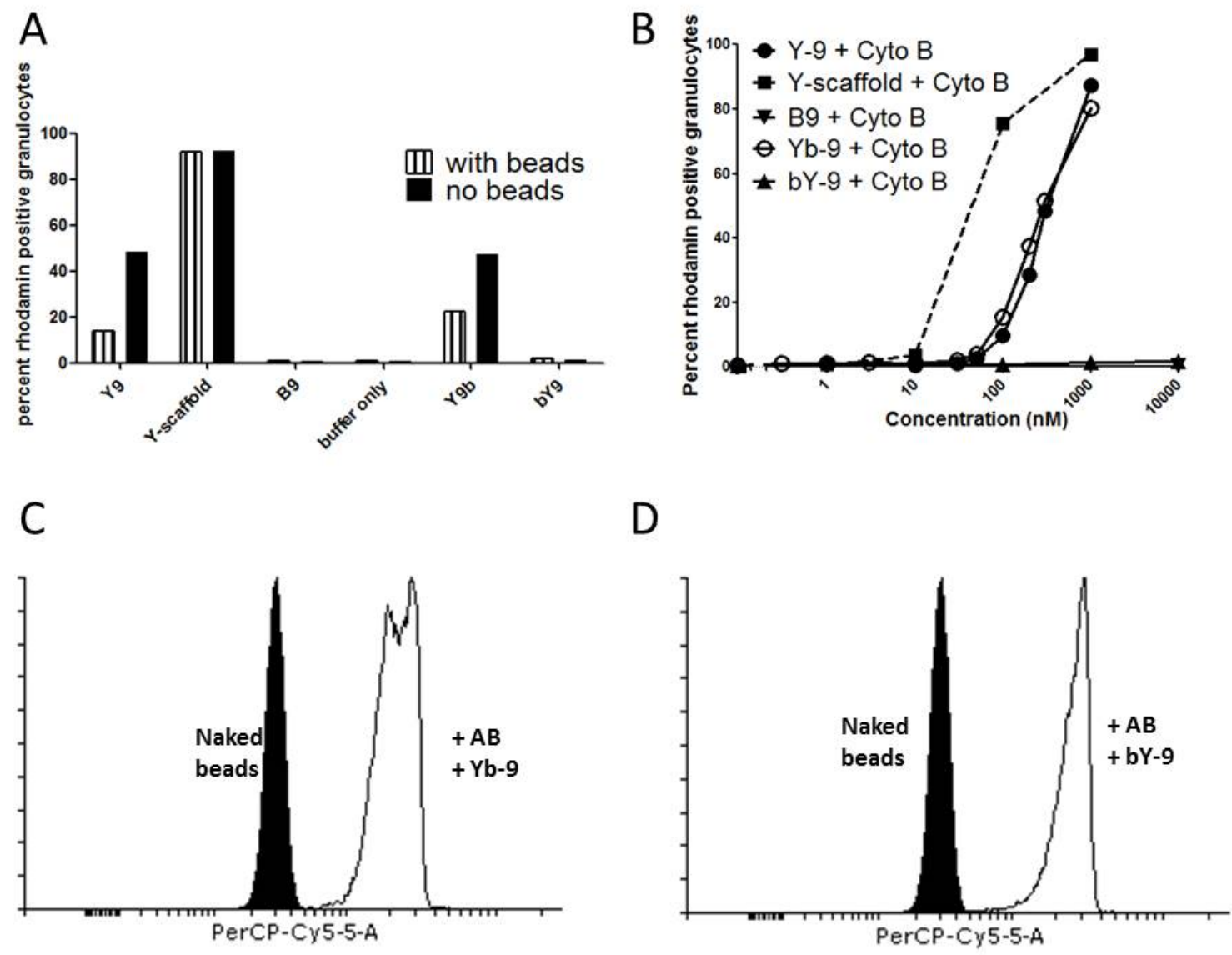

Figure S3. Binding of Y-9 and Yb-9 to antibody-loaded protein A beads. Panel A demonstrates the binding of Yb$\mathbf{9}$ and Y-9 but not Y-scaffold by protein A beads coated with a rabbit anti-B9 antibody. Two mg of antibody-coated beads were added to $75 \mathrm{pmol}$ of the indicated substances (or to buffer only) in $50 \mu \mathrm{l}$. The supernatants of the incubations with beads (striped bars) were added into DHR oxidation assays and the activation levels were compared with the original solutions (black bars), which should have a $300 \mathrm{nM}$ concentration in the assay (75 pmol in $250 \mu \mathrm{l}$ ). The measured activation levels before and after bead incubations can be compared with those caused by concentration ranges of the compounds in solution tested the same day with the same leukocytes (Panel B). B9 and bY-9 do not have activity in these assays but are supposed to bind the beads as well as $\mathbf{Y - 9}$ or $\mathbf{Y b}-\mathbf{9}$. Y-scaffold bears the neutrophilactivating effector peptide but lacks a $\mathbf{B 9}$ peptide and so does not bind and is not depleted by the beads. Panels $\mathrm{C}$ and D demonstrate the presence of biotinylated compounds Yb-9 and bY-9 on the surface of beads. Streptavidin-PerCPCy5.5 was used to stain beads loaded with anti-B9 antibody plus Yb-9 (C, open histogram) or bY-9 (D, open histogram) and compared with naked beads stained with streptavidin (filled histograms).

\section{Estimation of the amounts binding to protein $A$ beads}

Whereas the original solutions containing 75 pmol of either ISEr caused around 50\% rhodamine-positive neutrophils in a DHR assay (the equivalent of $300 \mathrm{nM}$, see panel B), the supernatants after incubation with $2 \mathrm{mg}$ of beads caused between 10 and $30 \%$ positive cells (the equivalent of 100-200 nM) in a series of four experiments done (panel A shows the results of two of these). This indicates that between 30 and 70\% of the $\mathbf{Y}-\mathbf{9}$ or $\mathbf{Y b} \mathbf{\mathbf { b }} \mathbf{9}$ was adsorbed by the antibodycoated beads. The actual capacity is therefore between 15 and 20 pmol ISEr per mg beads, a little lower than the theoretical maximum capacity of $8 \mu \mathrm{g}=53 \mathrm{pmol}$ IgG (150 $000 \mathrm{~g} / \mathrm{mol})$ per mg beads. The antibody is polyclonal and thus is not expected to be monospecific for $\mathbf{B 9}$ or $\mathbf{Y}-\mathbf{9}$. 
A

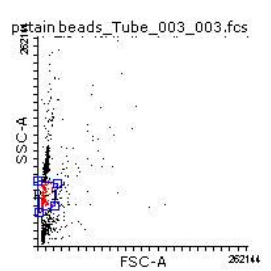

D

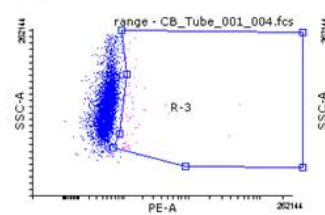

G

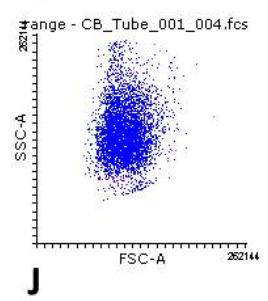

J

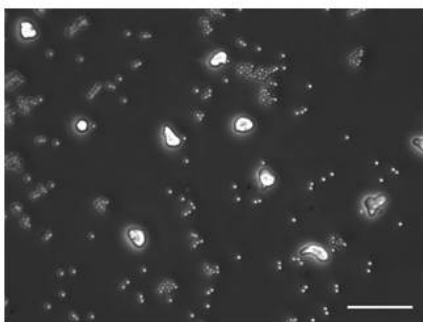

B

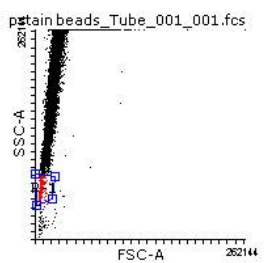

E
C

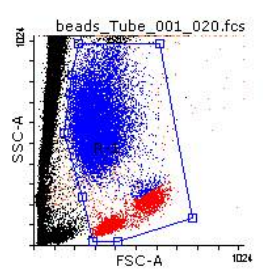

F
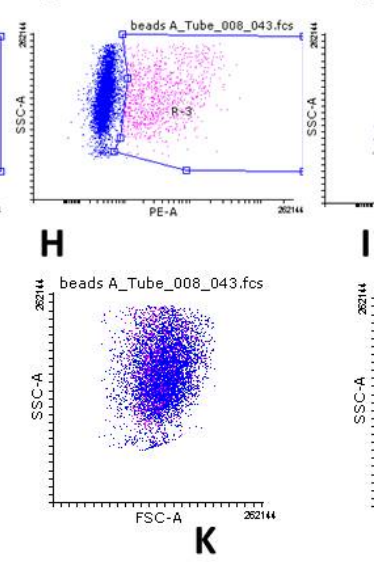

E beads B_Tube_008_051.fcs
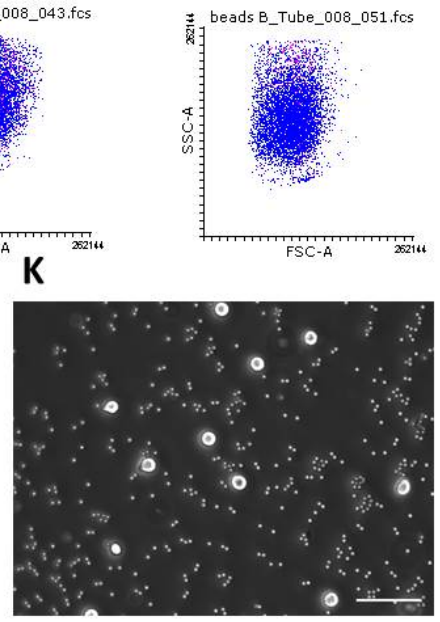

Figure S4. Details on the assays using ISEr-loaded protein A beads. A and B: Examples of the gating of single protein A beads for the purpose of staining biotinylated compounds on the surface of these beads (Fig. S3 C and D). A: naked beads; B: beads loaded with anti-B9 antibody plus Yb-9. Beads coated with the antibody always had a higher proportion of aggregates: $97 \%$ of all events recorded of the naked bead samples were single, while in the bead samples with antibody plus Yb-9 or bY-9 48 and 40\% resp. of all events were in the single bead gate. C: Gating of leukocytes in a sample incubated with protein A beads loaded with antibody and Yb-9. Beads (single and aggregated ones, observed in the left-hand margin of the plot) were gated out before proceeding with the gating of granulocytes and live neutrophils as in Fig. S1 A and B. In samples which had received more than $0.25 \mathrm{mg}$ of beads, the leukocyte gate was defined before acquisition and only events within the leukocyte gate were recorded and stored, in order to prevent the files becoming too large. D-F: Examples of the analysis of phagocyte NADPH oxidase in neutrophils after incubation with beads. Panel D shows a sample that was incubated with buffer only (negative control); panel E: incubated with 1 mg of beads loaded with antibody + Yb-9; panel F: incubated with 1 mg of beads loaded with antibody + bY-9. G-I: Examples of the analysis of shape change of neutrophils. Panel G shows a sample that was incubated with buffer only (negative control); panel H: incubated with $1 \mathrm{mg}$ of beads loaded with antibody + Yb-9; panel I: incubated with $1 \mathrm{mg}$ of beads loaded with antibody $+\mathbf{b Y}-\mathbf{9}$. J and K: Photomicrographs (inverted microscope with phase contrast, white size bars represent $50 \mu \mathrm{m}$ ) illustrating the shape change of human leukocytes (mainly neutrophils) incubated with 0.5 mg of beads loaded with antibody plus Yb-9 (J, irregular cells) or B9b (K, round cells) in the absence of cytochalasin B. After the assay cells were fixed in $1 \%$ formaldehyde and put into a Neubauer chamber $(0.1$ mm thickness) in the presence of trypan blue (to show that the cells are alive). The small dots are the protein A beads with a diameter of 2.8 $\mu \mathrm{m}$. 

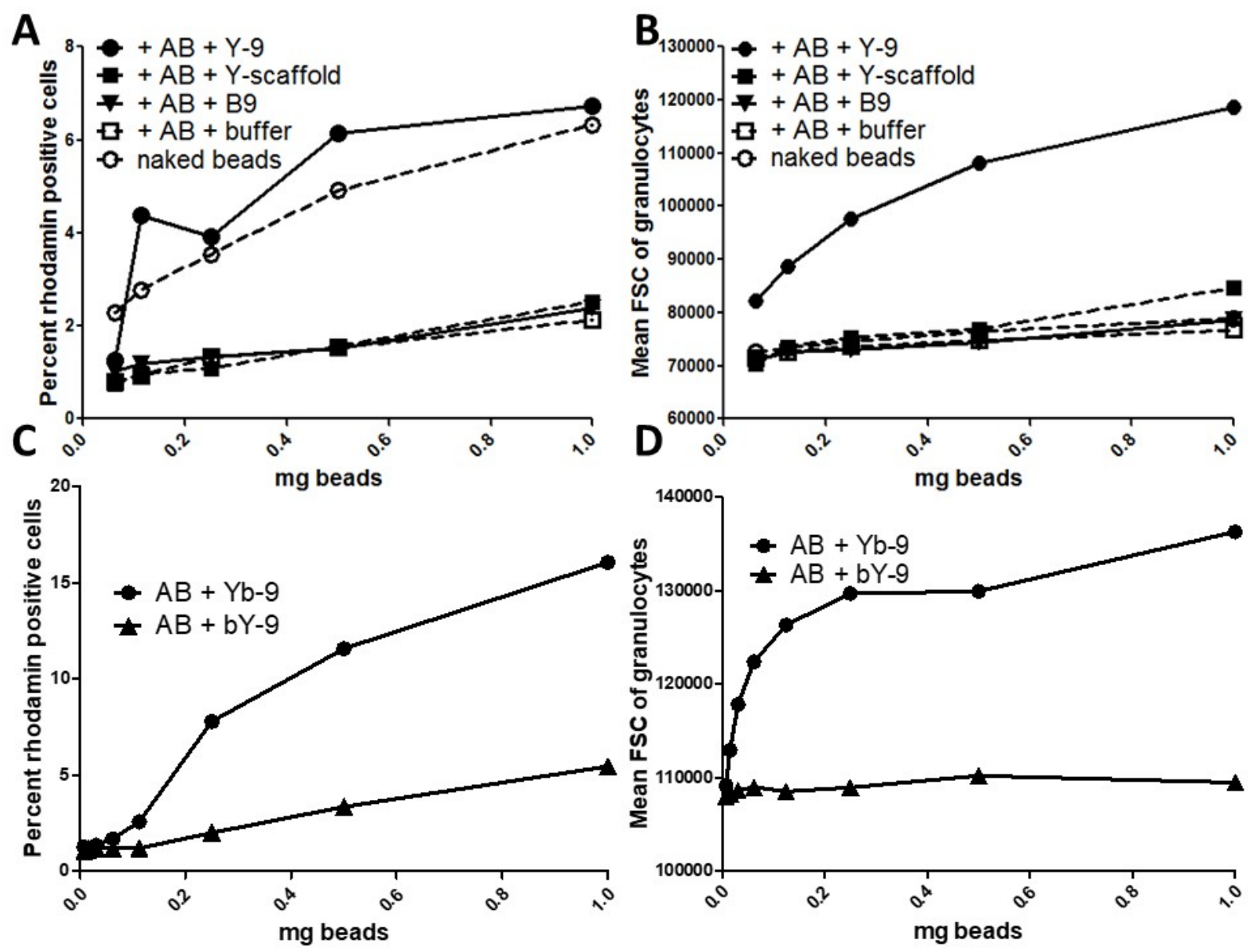

Fig. S5A. Neutrophil activation as a function of protein A bead amounts. Protein A beads were incubated with (or without: naked beads) the anti-B9 antibody, and subsequently with the compounds as indicated in the panel legends. Increasing amounts of beads ( $7.8 \mu \mathrm{g}$ up to $1 \mathrm{mg}$ ) were added to the immune cell samples. Two independent experiments are shown in panels A-B and in panels C-D. Panels A and C show the effects on activation of the NADPH oxidase in neutrophils; panels $\mathrm{B}$ and $\mathrm{D}$ show the effects on shape change of neutrophils.

Both experiments show a trend of increasing granulocyte activation levels with increased amount of beads carrying immune-active ISEr on the beads. When added in large amounts (0.5-1 mg), also “ control” coated beads (incubated with Y-scaffold (not binding the antibody), B9, bY-9 (not carrying an N-formylated peptide), antibody only (AB + buffer)) can induce a low level of oxidase activation (1-8\% of rhodamine-positive neutrophils with $0.5 \mathrm{mg}$ "control" coated beads vs. 4-15\% positive neutrophils with $0.5 \mathrm{mg}$ Y-9 or Yb-9 coated beads and 0-2\% positive neutrophils in buffer in a series of four experiments), while naked beads strongly do so (similar activation levels as Y-9 coated beads in Fig. S5A). This appears to be an intrinsic drawback of the protein A bead model, as explained in the main text. 

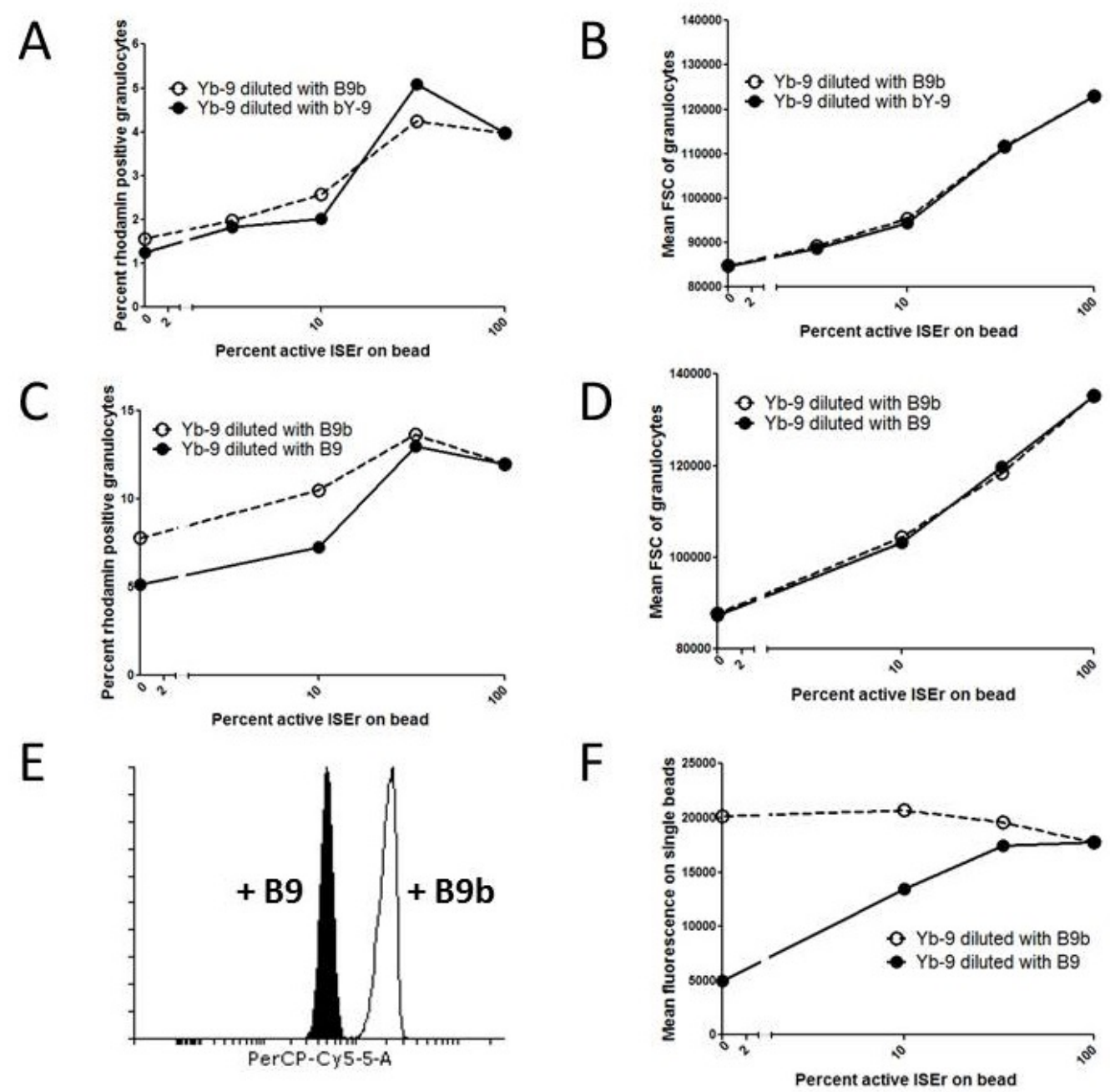

Figure S5B. Neutrophil activation as a function of density of active ISEr loaded on antibody-coated protein A beads. In all cases, $0.5 \mathrm{mg}$ of beads were added to each sample. Two independent experiments are shown in panels A$\mathrm{B}$ and in panels C-F. Panels A and C show the effects on activation of the NADPH oxidase in neutrophils; panels B and D show the effects on shape change of neutrophils. FSC values in unstimulated neutrophils were 82400 and 84600 in the experiments leading to panels B and D, respectively. In A and B protein A beads coated with anti-B9 antibody were incubated with Yb-9, bY-9, B9b or with mixtures of $\mathbf{Y b} \mathbf{- 9}$ and one of the other compounds in different ratios with the purpose of obtaining beads with varying surface densities of the active $\mathbf{Y b}-\mathbf{9}$. In C and D protein A beads coated with anti-B9 antibody were incubated with Yb-9, B9b, B9 or with mixtures of Yb-9 and one of the other compounds in different ratios. Panels E-F show streptavidin staining of beads. Panel $\mathrm{E}$ is an overlay histogram showing the fluorescence caused by binding of $\mathbf{B 9 b}$ to the beads (open histogram) and the much lower fluorescence of beads loaded with non-biotinylated $\mathbf{B 9}$ (filled histogram) representing the background level which is similar to that observed with naked beads in Fig. S3 C-D. The presence of Yb-9 and bY-9 on bead surfaces was already shown by streptavidin staining in Fig. S3 C-D. In panel F the mean fluorescences of the beads loaded with the various compounds in different ratios is plotted. It demonstrates i) the gradual replacement of $\mathbf{Y b - 9}$ by $\mathbf{B 9}$ with increasing amounts of $\mathbf{B 9}$ in the mixture, and ii) a higher biotin level on beads covered with $\mathbf{B 9} \mathbf{b}$ than on beads covered with $\mathbf{Y b} \mathbf{\mathbf { b }} \mathbf{9}$, likely caused by the differing peptide/biotin ratios of the single peptide and the dimeric ISEr.

Both experiments show a trend of increasing granulocyte activation levels with increased density of the active ISEr on the beads. The low percentages of rhodamine-positive cells caused by beads coated with inactive compounds only (bY-9, B9b or B9) are an intrinsic drawback of the protein A bead model, as explained in the main text. 

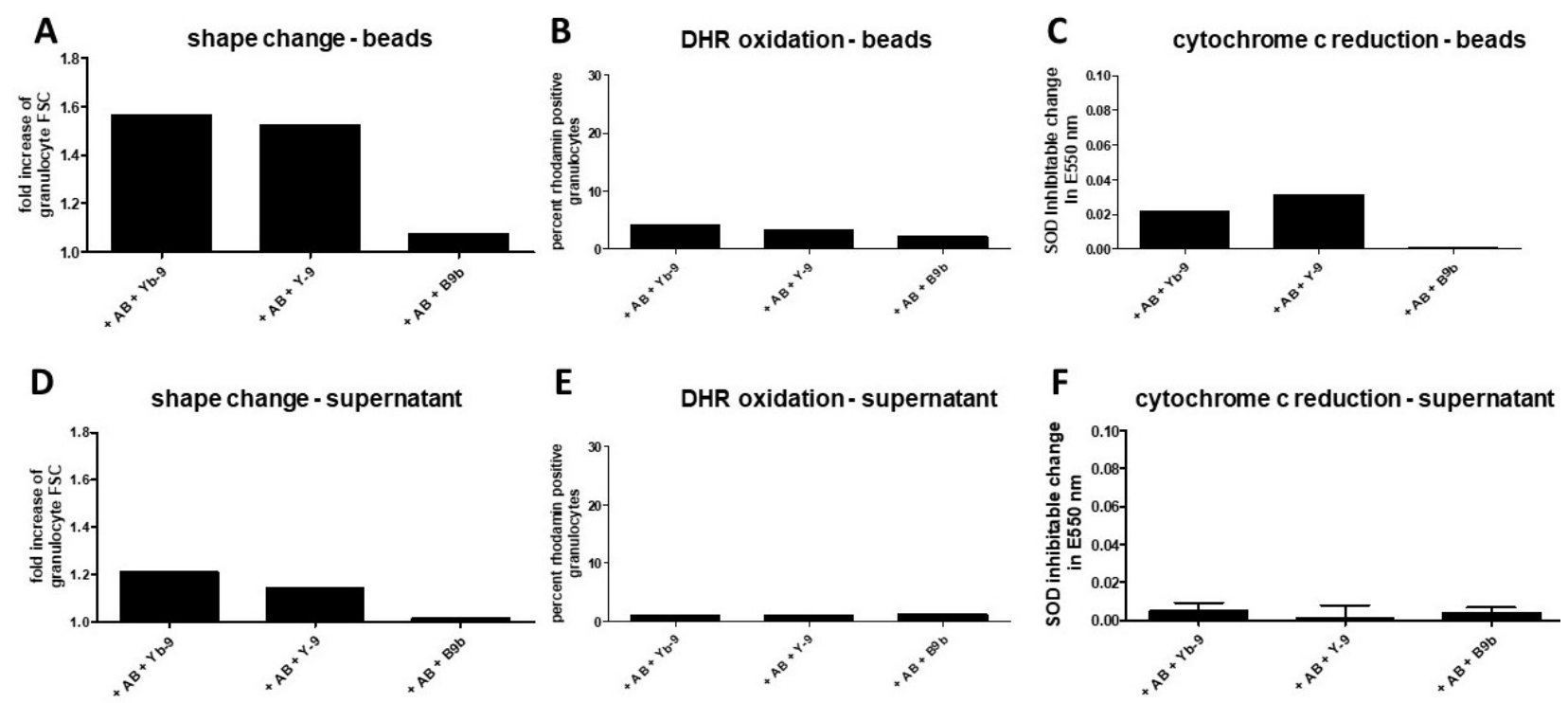

Figure S5C. Direct comparison of three assays to assess neutrophil activation by ISEr-coated protein A beads or their supernatants at $37^{\circ} \mathbf{C}$. Protein A beads coated with anti-B9 antibody and then with $\mathbf{Y b} \mathbf{b} \mathbf{9}, \mathbf{Y}-\mathbf{9}$ or $\mathbf{B 9 b}$, or their supernatants after $20 \mathrm{~min}$ at $37^{\circ} \mathrm{C}$, were tested for neutrophil activation in the neutrophil shape change assay (panels A and D), the DHR oxidation assay (panels B and E) and the cytochrome c reduction assay (panels C and F) in parallel (the same bead preparations and supernatants were tested at the same moment with the same batch of human leukocytes) in the absence of cytochalasin B. Similar to what is shown in Fig. 3 A and B, Yb-9 and Y-9 coated beads caused a rise in granulocyte FSC (panel A) and a minor rise in the percentage of rhodamin-positive granulocytes (panel B) when compared with control B9b-coated beads. Similar to results summarized in Fig. $3 \mathrm{C}$ and $\mathrm{D}$, the $37^{\circ} \mathrm{C}$ supernatants of Y-9 and Yb-9 loaded beads caused a minor rise in granulocyte FSC (panel D) but no increase of rhodamin-positive cells (panel E). The cytochrome c reduction assay also showed minor signs of cytochrome c reduction by the Yb-9 and Y-9 coated beads (panel C; compare with Fig. S1 panel N, which indicates that an absorbance change of up to $0.08-0.1$ is reached upon full stimulation) but no cytochrome c reduction by their $37^{\circ} \mathrm{C}$ supernatants (panel F). 


\section{A Depletion by strep beads}

\section{B Activation with beads}

\section{Activation with beads}
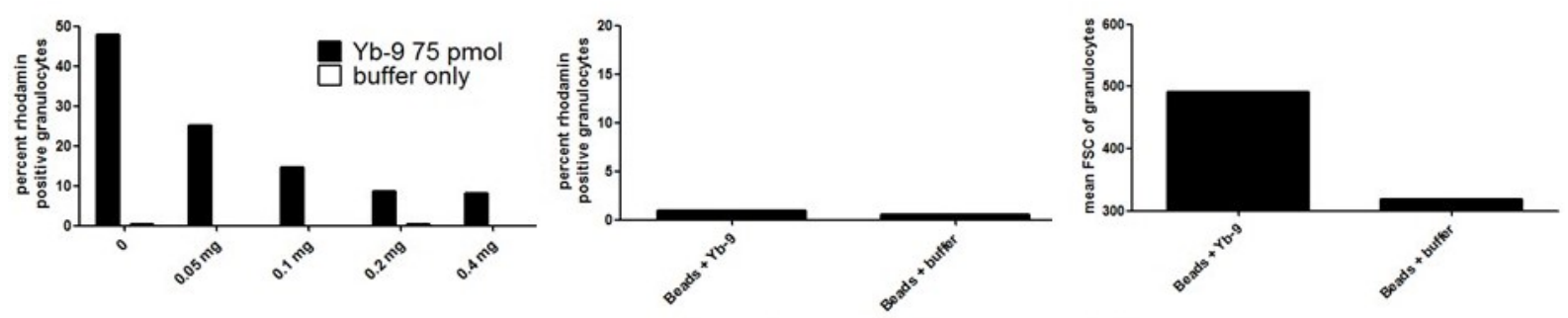

\section{Complexation with soluble streptavidin}
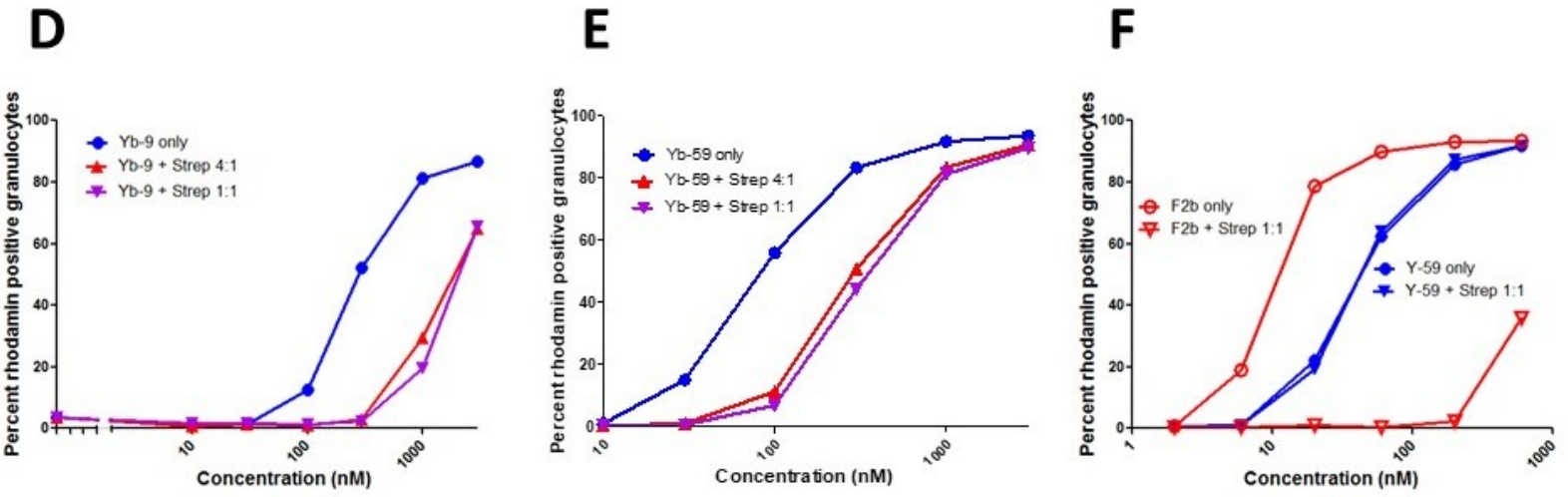

Figure S6. Depletion of Yb-9 by streptavidin beads, activation of neutrophils by Yb-9 loaded streptavidin beads and the effect of complexing biotinylated ISErs/effector peptide with soluble streptavidin on their potencies. A: Samples containing 75 pmol Yb-9 or buffer only were incubated with different amounts (0-0.4 mg) of streptavidin beads and supernatants after pelleting the beads were measured in the DHR oxidation assay in the presence of cytochalasin B. Maximum depletion of activity was reached with 0.2 and $0.4 \mathrm{mg}$ beads. No activation was observed with buffer only incubated without or with $0.2 \mathrm{mg}$ beads. B and C: DHR oxidation assay and shape change assay in the absence of cytochalasin B testing the effects on granulocytes of $0.2 \mathrm{mg}$ of streptavidin beads that were preincubated with 60 pmol Yb-9 or with buffer only. B: DHR oxidation assay. No activation by Yb-9 loaded beads was observed. C: Neutrophil shape change assay. An increase in granulocyte FSC was observed with Yb-9 loaded beads but not with buffer-incubated beads. The mean FSC value was 316 in the unstimulated sample (buffer only, not shown). D-F: Dose-effect curves of Yb-9, Yb-59, Y-59 (a non-biotinylated variant of Yb-59) and F2b (biotinylated peptide F2) in the DHR oxidation assay in the presence of cytochalasin B, either alone (0) or after pre-incubation with soluble streptavidin (ImmunoPure streptavidin, Thermo Scientific) at molar ratios 4:1 (theoretically yielding tetrameric complexes) or 1:1. Complexation with streptavidin of all biotinylated compounds led to a loss in potency (3-50-fold) irrespective of the molar ratio, while the potency of non-biotinylated $\mathbf{Y}-\mathbf{5 9}$ was not affected by streptavidin at all (blue curves in panel F). 

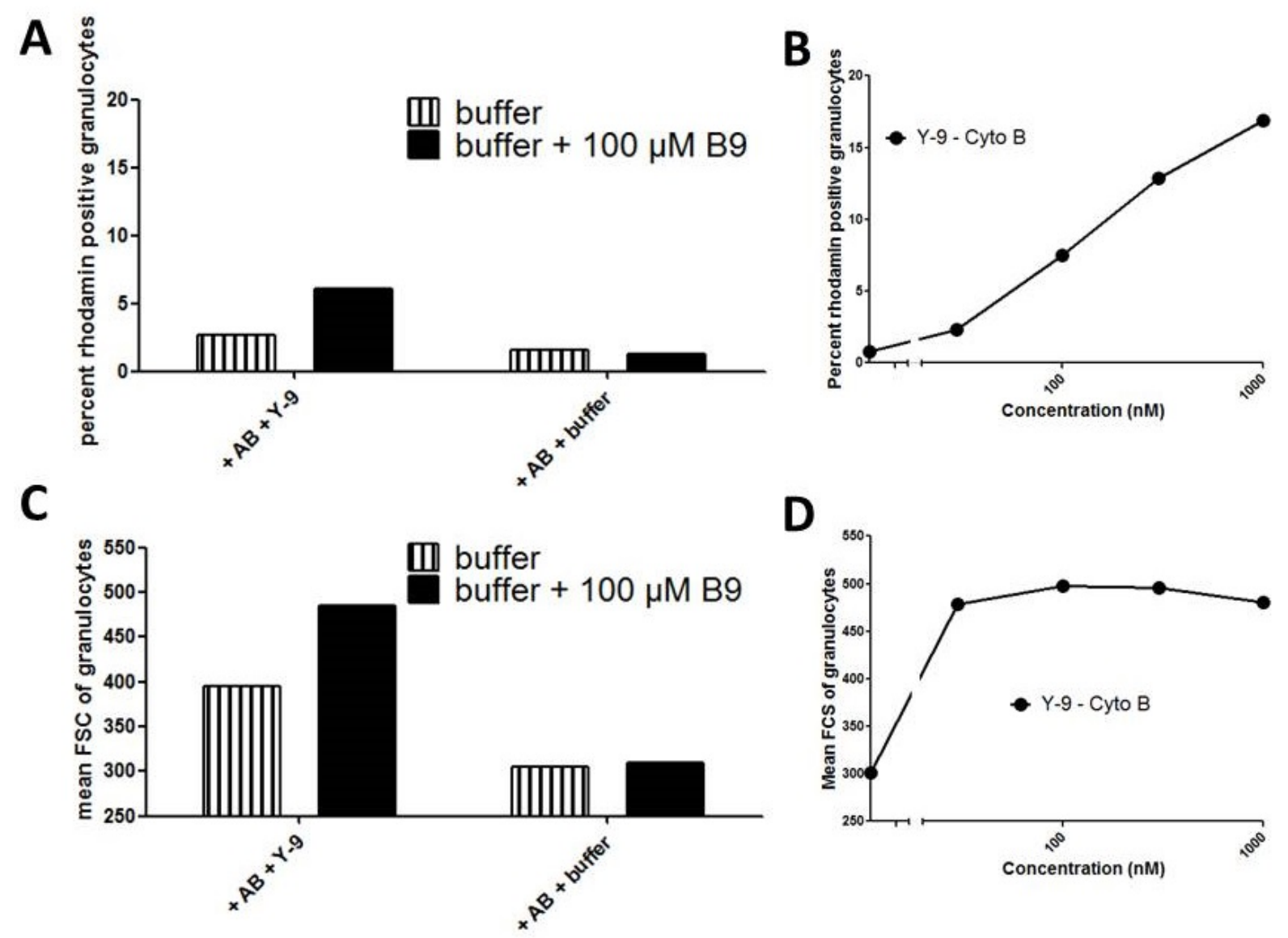

Figure S7. Forced release of Y-9 from protein A beads. Protein A beads (4 x $1.25 \mathrm{mg}$ ) were loaded with anti-B9 antibody and then incubated with either $\mathbf{Y}-\mathbf{9}$ (2 portions) or with assay buffer only (2 portions). After thorough washing of the beads, they were incubated for 150 min at ambient temperature in $125 \mu \mathrm{L}$ assay buffer only or in assay buffer containing $100 \mu \mathrm{M}$ B9 peptide. Beads were pelleted and the supernatants were added to the activation assays. Top: Activation of NADPH oxidase by the bead supernatants (panel A) and the dose-effect curve of soluble $\mathbf{Y}-\mathbf{9}$ for the purpose of calibration (panel B). Bottom: Granulocyte shape change induced by the bead supernatants (panel C) and the dose-effect curve of soluble $\mathbf{Y}-\mathbf{9}$ for the purpose of calibration (panel D).

\section{Estimation of the amounts released from protein A beads}

The bead supernatants containing $100 \mu \mathrm{M}$ B9 peptide caused the maximum FSC increase (indicating at least $30 \mathrm{nM}$ of soluble Y-9) and 6\% rhodamine-positive neutrophils (indicating almost $100 \mathrm{nM}$ of Y-9). Supernatants of the control beads did not lead to any activation, hence competitor peptide $\mathbf{B 9}$ did not possess any activity. The results indicate that Y-9 can be efficiently displaced from the binding site on the anti-B9 antibody using an excess of B9 peptide. The Y-9 amount rescued from $1.25 \mathrm{mg}$ beads after displacement can be estimated to be $7.5-25 \mathrm{pmol}(30-100 \mathrm{nM}$ in a $0.25 \mathrm{~mL}$ assay volume), which is in accordance with the estimated adsorption of 15-20 pmol per mg beads (see Fig. S3). 
Yb-9 vs. Yb-scaffold

B9b vs. Yb-scaffold

A431

PC-3
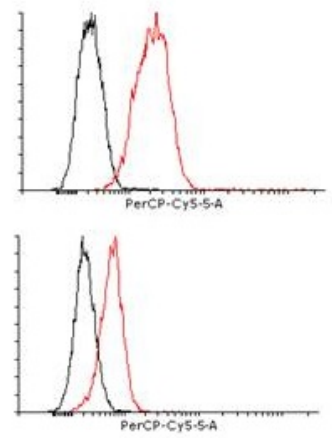

Yb-9 vs. Yb-scaffold

B9b vs. Yb-scaffold
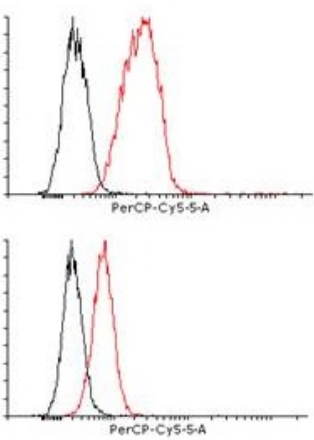

K562

L-929
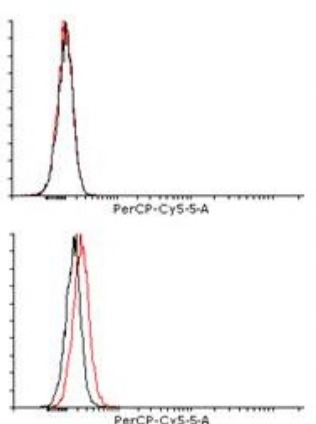
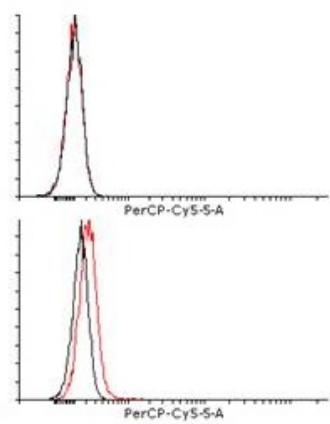

Figure S8. Demonstration of binding of Yb-9 and B9b to cell lines. Staining with streptavidin-PerCP-Cy5.5 of cell surface bound Yb-9 or B9b (red histograms) is compared with non-binding Yb-scaffold (black histograms) on four cell lines after incubation with the compounds on ice and thorough washing at $0-4^{\circ} \mathrm{C}$. These are the cells as they entered the activation assays shown in Fig. 4A. 


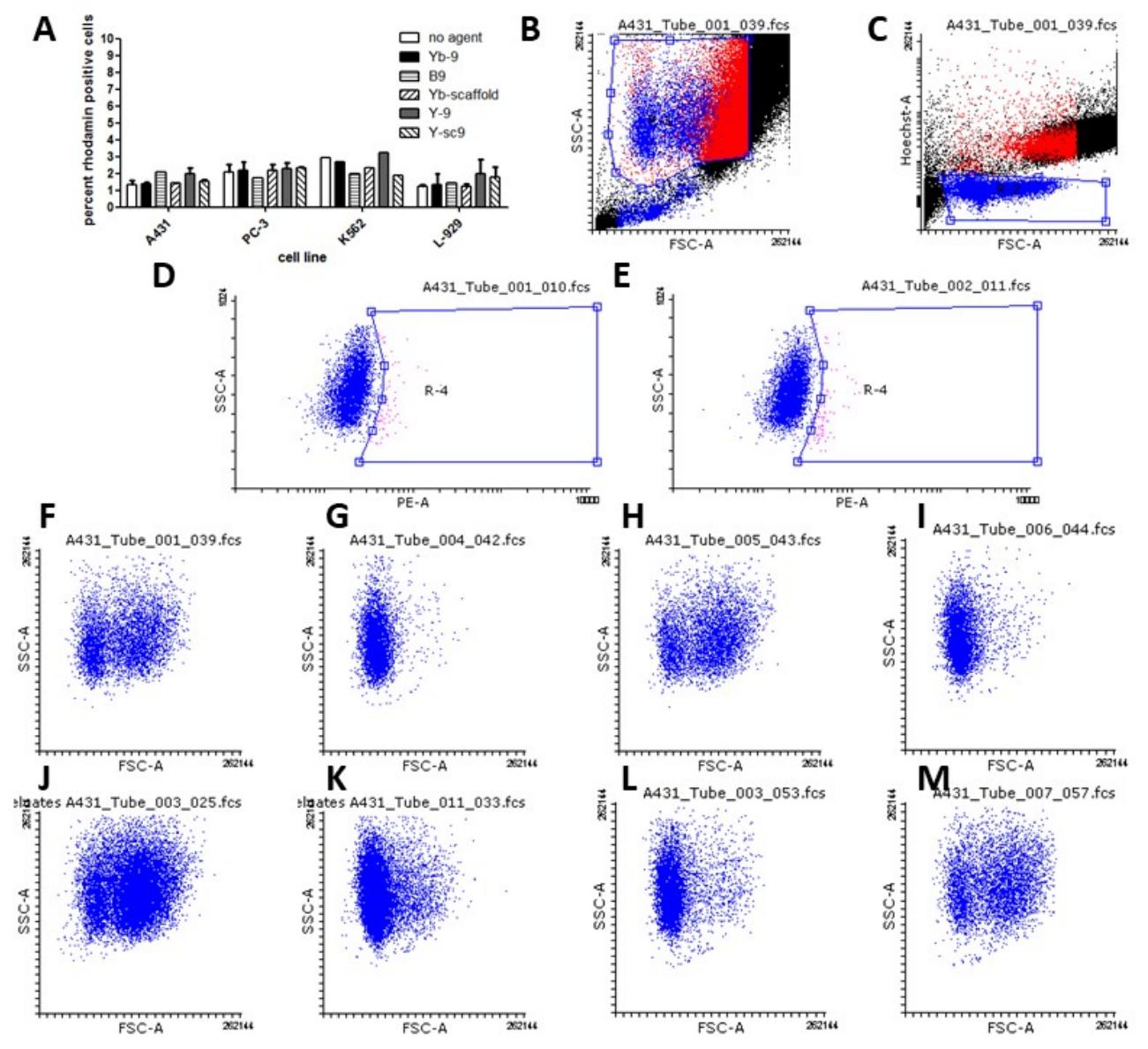

Figure S9. Additional data on the activation of neutrophils by tumor cells incubated with integrin-binding ISErs. Panel A shows the absence NADPH oxidase activation after incubation of leukocytes with 2-2.5 million tumor cells incubated with the ISErs or control substances (shown are means and standard deviations of the percentage of rhodamine-positive neutrophils of $n=2$ experiments, $n=1$ experiment with $K 562$ cells). B-M: Examples of granulocyte activation assays run with ISEr-loaded cell lines. Panels B and C show the gating of live neutrophils in a sample also containing also Yb-9-loaded A431 tumor cells. In the FSC/SSC plot (B) activated neutrophils (with a high FSC, here: blue) overlap with a part of the A431 cells in the sample (red) and so it is impossible to use a granulocyte region that is not contaminated with tumor cells using this scatter plot only. In the FSC/Hoechst plot (C) both eosinophils (nonreactive to F2 and ISErs, also see Fig. S1B) and tumor cells have a higher autofluorescence than all other live leukocytes, and so they can be separated using a second region in this plot (creating the blue population). The neutrophils to be analyzed thus have to be within the granulocyte gate (R1) in the FSC/SSC plot and within the live leukocyte gate (R2) in the FSC/Hoechst plot. Panels D and E show the absence of activation of NADPH oxidase in neutrophils incubated with Yb-9-coated A431 cells (D) as compared with naïve A431 cells (E). Oxidase-positive cells would have been detectable in the R4 region in the PE/SSC plot. Panels G-J demonstrate shape change/FSC increase of neutrophils incubated with Yb-9 (F) or Y-9 (H)-loaded A431 cells but not with naïve (G) or Y-sc9-incubated (I) A431 cells. Panels $\mathrm{J}$ and K show the FSC changes of neutrophils incubated with the supernatants of Y-9-coated A431 cells incubated for $20 \mathrm{~min}$ at $37^{\circ} \mathrm{C}$ (J, activated) or $0^{\circ} \mathrm{C}$ (K, not activated) after washing. Panels $\mathrm{L}$ and $\mathrm{M}$ show FSC changes after incubation with the $\mathbf{Y}$-9-coated A431 cells after an extended 20 min incubation at $37^{\circ} \mathrm{C}$ (L, no activation, no more Y-9 is expected on the cell membranes) or $0^{\circ} \mathrm{C}$ (M, activation, Y-9 is still expected on the cell membranes) and subsequent removal of their supernatants (shown in $\mathrm{J}$ and $\mathrm{K}$ ) and resuspension in fresh assay buffer. 
A. Yb-9 vs. no agent

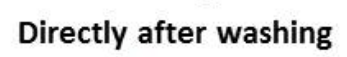

A431

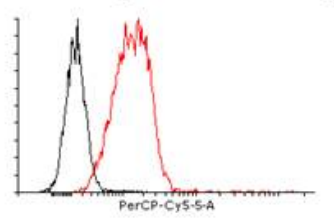

PC-3

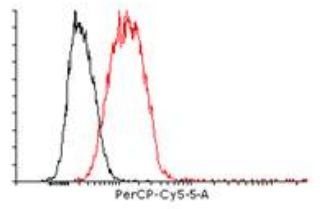

B.

Yb-9 vs. Y-sc9

Directly after washing

A431

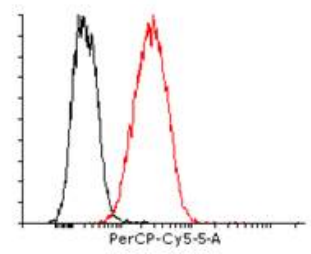

PC-3

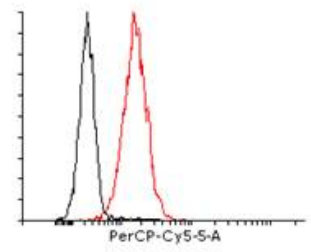

After $10 \mathrm{~min} .37^{\circ} \mathrm{C}$
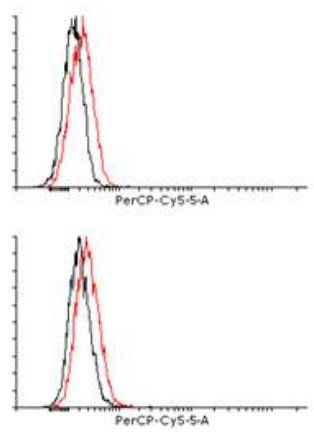

After $\mathbf{2 0 ~} \mathrm{min} . \mathbf{3 7 ^ { \circ } \mathrm { C }}$
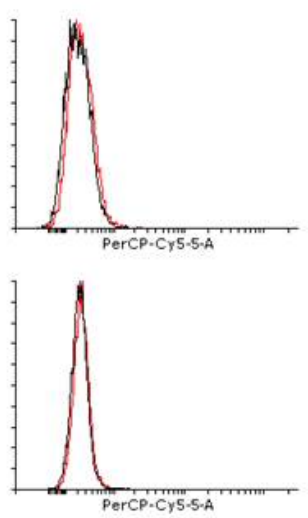

After $20 \mathrm{~min} .37^{\circ} \mathrm{C}$
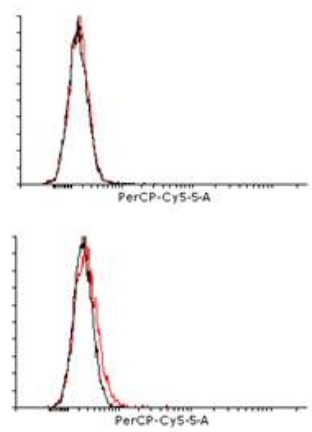

After $20 \mathrm{~min} .0^{\circ} \mathrm{C}$
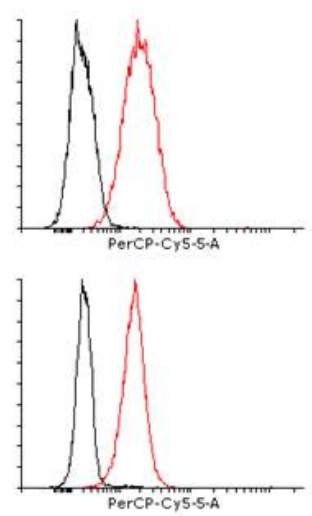

Figure S10. Demonstration of the disappearance of cell membrane-bound $\mathrm{Yb}-9$ at $37^{\circ} \mathrm{C}$. Staining with streptavidin-PerCP-Cy5.5 of cell surface $\mathbf{Y b - 9}$ (red histograms) as compared with naïve cells (A, black histograms) or non-binding and non-biotinylated Y-sc9 (B, black histograms) on A431 or PC-3 cells after incubation with the compounds on ice and thorough washing at $0-4^{\circ} \mathrm{C}$. The cells directly after washing, as they entered the activation assays ( $\mathrm{t}=0$ ) are depicted in the left-hand panels. Cells incubated for 10 or $20 \mathrm{~min}$ in assay buffer either at $37^{\circ} \mathrm{C}$ or at $0^{\circ} \mathrm{C}$, and then put back on ice and stained with streptavidin are shown in the middle and right-hand panels, as indicated in the figure.

\section{Estimation of the amount of integrin-binding ISEr bound to and released by tumor cells}

The release of activity from the $\mathbf{Y}-\mathbf{9}$ and $\mathbf{Y b} \mathbf{\mathbf { 9 }} \mathbf{9}$ incubated cells at $37^{\circ} \mathrm{C}$ (Fig. 5) correlated with the disappearance of the cell surface signals of $\mathbf{Y b}-\mathbf{9}$ at $37^{\circ} \mathrm{C}$ (Fig. S10 above) suggesting that simple dissociation of ISErs from the receptors is the major cause of activity release at $37^{\circ} \mathrm{C}$. The activation levels induced by the tumor cell supernatants, represented by 1.15 to 1.6 fold increases of neutrophil FSC, suggest that ISEr concentrations between 3 and $10 \mathrm{nM}$ were present in the $0.25 \mathrm{~mL}$ assay volumes - normalized and averaged dose-effect curves of $\mathbf{Y}-\mathbf{9}$ and $\mathbf{Y b} \mathbf{\mathbf { b }} \mathbf{9}$ tested in the same experiments are shown in Fig. S1H for the sake of calibration. The amounts released by the $2-2.5 \times 10^{6}$ cells in each sample thus appear to be in a range of between 0.75 and 2.5 pmol of ISEr. Since the binding of these ISErs was specific (no binding was detected on and no activity was released from control cells incubated with the same ISErs) one can estimate that between 180000 and 750000 ISErs were released from each cell, and that at least these numbers of receptors (integrin $\alpha 3$ chains) should be present per cell. No published data on the numbers of integrin $\alpha 3$ proteins expressed per A431 or PC-3 cell are known to us that could be used for comparison. 
A

PC-3 Yb-59I vs. no agent

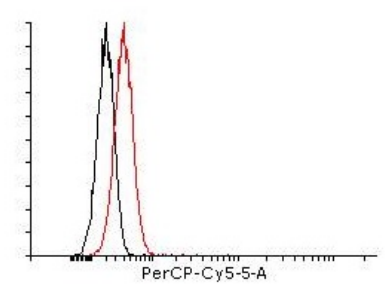

K562

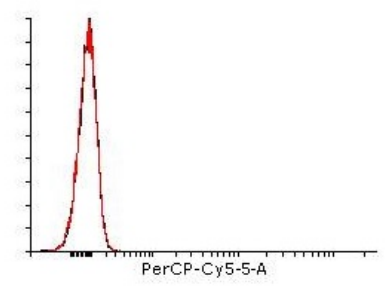

Tet-Yb-59l vs. no agent
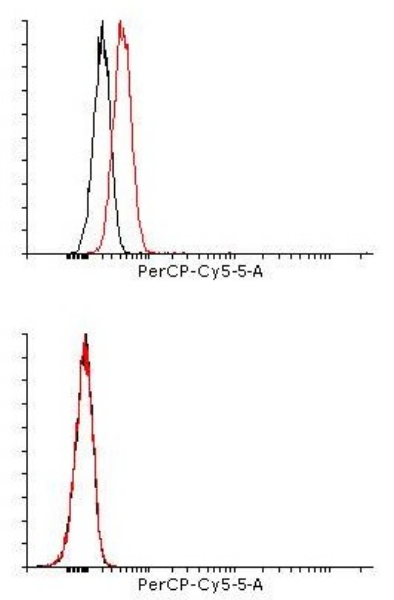

Yb-sc59 vs. no agent
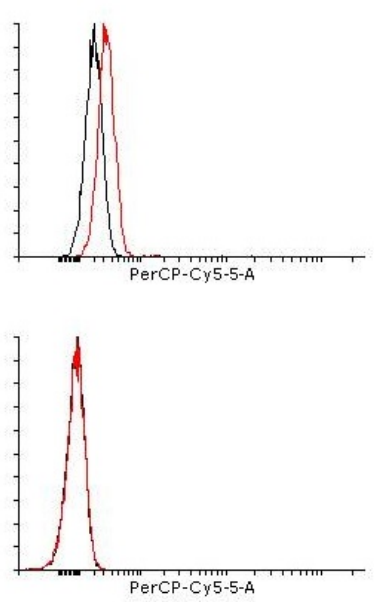

Figure S11A. Demonstration of binding of Yb-59, Tet-Yb-59 and Yb-sc59 to PC-3 cells. Staining with streptavidin-PerCP-Cy5.5 of cell surface bound $\mathbf{Y b}$-59, Tet-Yb-59 and $\mathbf{Y b}$-sc59 (red histograms) was compared with no agent added (black histograms) on two cell lines after incubation with the compounds on ice and thorough washing at $0-4^{\circ} \mathrm{C}$. These are the cells as they entered the activation assays shown in Fig. 5B. Typical examples are shown of an experiment performed three times. 
B

$t=0$

Yb-59 vs. no agent

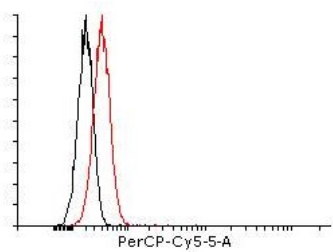

$20 \mathrm{~min}$.

$0^{\circ} \mathrm{C}$

$20 \mathrm{~min}$. $37^{\circ} \mathrm{C}$
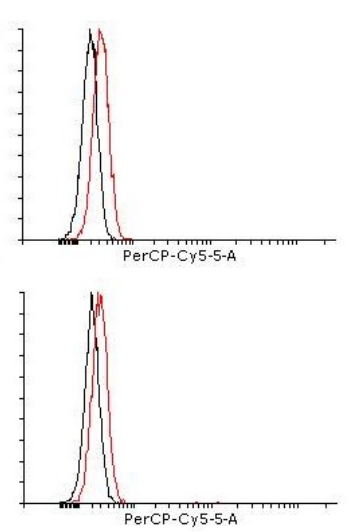

Tet-Yb-59 vs. no agent
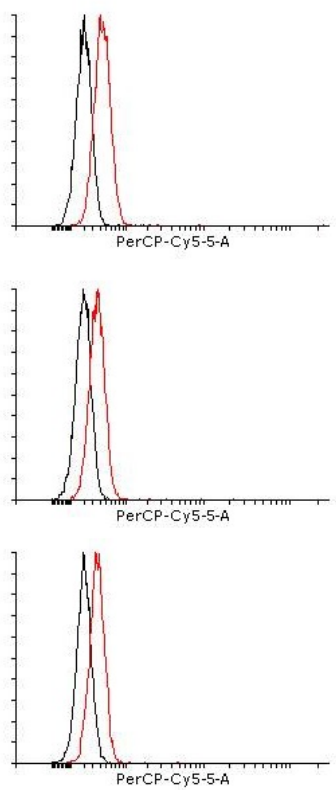

Yb-sc59 vs. no agent
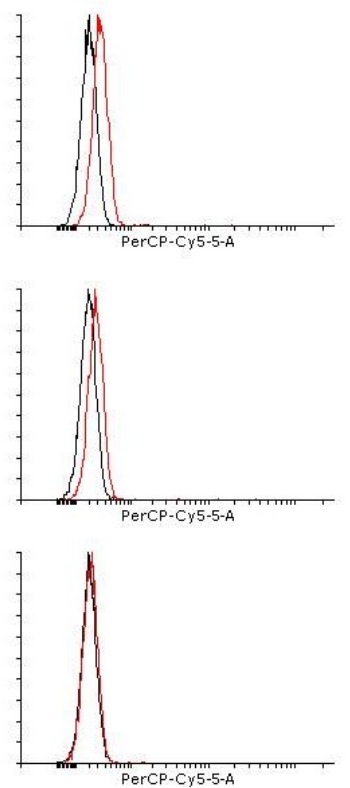

Figure S11B: Demonstration of the rate of disappearance of PC-3 cell membrane-bound Yb-59, Tet-Yb-59 or Yb-sc59 on ice or at $37^{\circ} \mathbf{C}$. Staining with streptavidin-PerCP-Cy5.5 of cell surface bound biotinylated ISErs (red histograms) was compared with naïve PC-3 cells (black histograms) after incubation with the compounds on ice and thorough washing at $0-4^{\circ} \mathrm{C}$. The cells directly after washing, as they entered the activation assays $(\mathrm{t}=0)$ are depicted in the top row. Cells incubated for 20 min in assay buffer either at $0^{\circ} \mathrm{C}$ or at $37^{\circ} \mathrm{C}$ were put back on ice and stained with streptavidin are shown in the middle and bottom panels, as indicated in the figure. Typical examples are shown of an experiment performed three times. Quantitation of the relative surface levels measured in three experiments is shown in Fig. 5A. 


\section{A Supernatants $0^{\circ} \mathrm{C}$ of ISEr incubated cell lines}

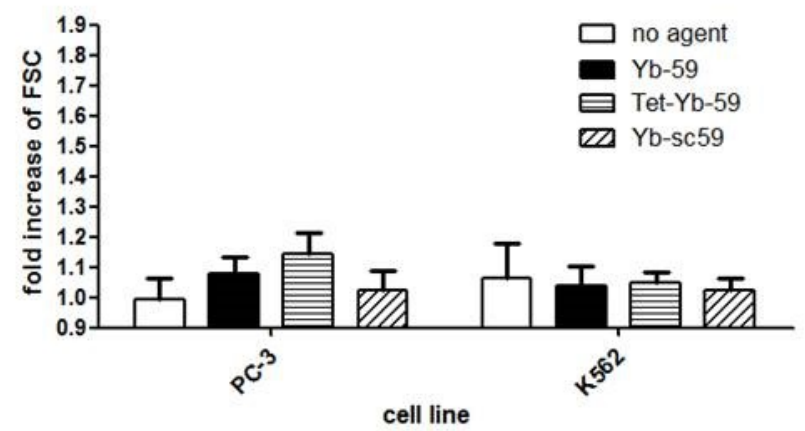

B ISEr incubated PC-3 cells

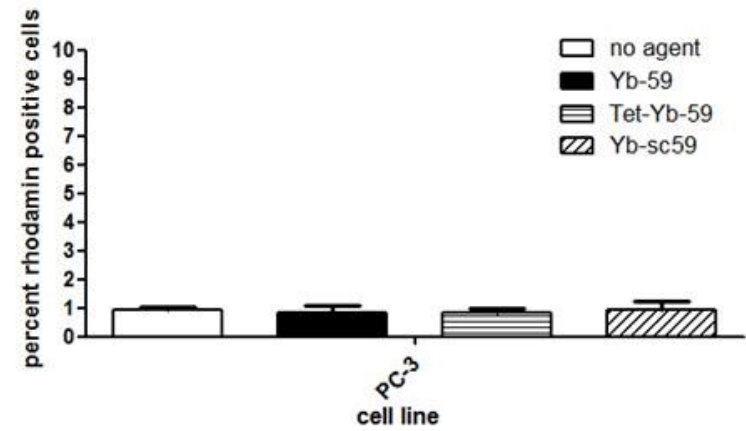

C Supernatants $37^{\circ} \mathrm{C}$ of ISEr incubated PC-3

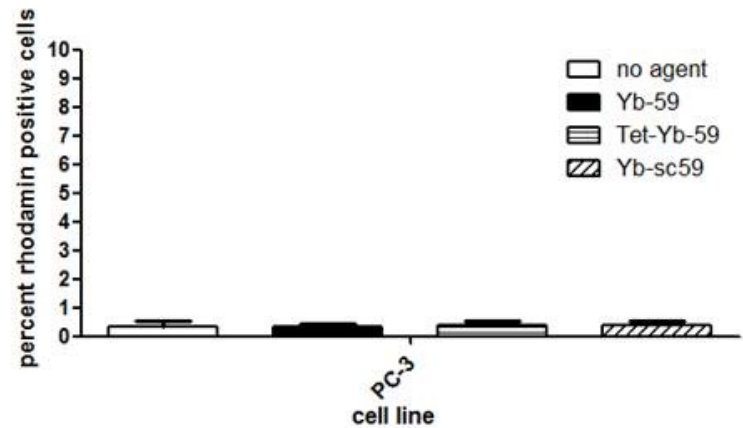

Figure S12. Additional immune activation assays using PC-3 cells incubated with EphA2 binding ISErs or supernatants thereof. A: Absence of neutrophil shape change induction by $0^{\circ} \mathrm{C}$ supernatants of PC-3 and $\mathrm{K} 562$ cells loaded with the indicated ISErs (addition to Fig. 5 panel $\mathrm{C}$ in which parallel $37^{\circ} \mathrm{C}$ supernatants did have this activity). $\mathrm{B}$ and C: Absence of activation of NADPH oxidase after incubation with ISEr-incubated PC-3 cells (B) or with $37^{\circ} \mathrm{C}$ supernatants of these cells (C), which did induce increases in neutrophil FSC as demonstrated in Fig. 5B and C. 

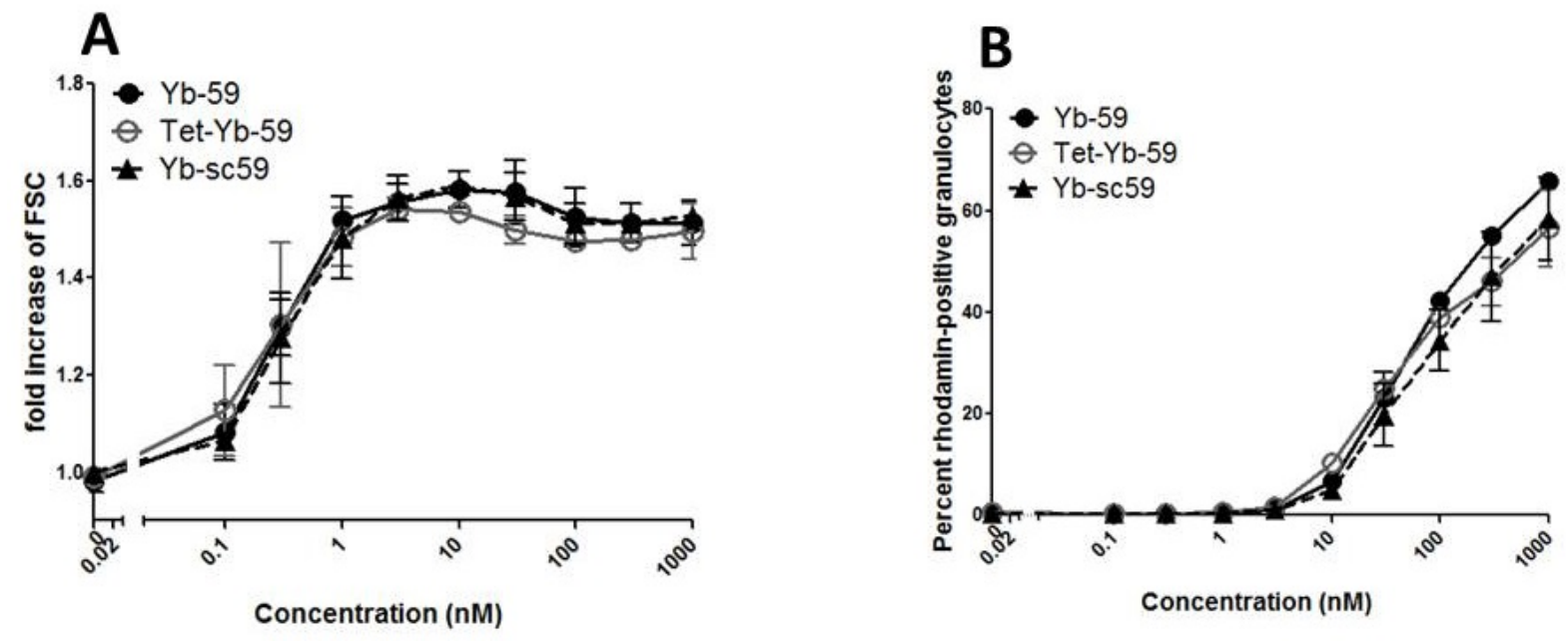

Figure S13. Dose effect curves showing the effects of increasing concentrations of soluble Yb-59, Tet-Y-59 and Yb-sc59. A: neutrophil FSC increases; B: percentage of rhodamine-positive neutrophils, both assay types performed in the absence of cytochalasin B. This is a compilation of the data acquired in a series of experiments leading also to Fig. 5 in which always two of the compounds were compared. Shown are the means and the standard deviations of two measurements for each compound. FSC data in panel A were normalized as described elsewhere. 


\section{Estimation of the amount of EphA2-binding ISEr bound to and released by tumor cells}

The material released by $\mathbf{Y b}-\mathbf{5 9}$ and Tet-Yb-59 incubated PC-3 cells at $37^{\circ} \mathrm{C}$ caused about 1.5 fold FSC increases, which suggests that at least $1 \mathrm{nM}$ of the ISEr was present in the $0.25 \mathrm{~mL}$ assay volumes when calibrated against doseeffect curves of these agents in solution (Fig. S13A). The lack of activation of the NADPH oxidase indicates that concentrations were lower than $10 \mathrm{nM}$ ISEr (Fig. S13B). If complete Yb-59 or Tet-Yb-59 was released from the PC3 cells at $37^{\circ} \mathrm{C}, 0.25-2.5$ pmol would be present, released from $2 \times 10^{6}$ cells. This would mean that $75000-750000$ ISEr molecules were released per cell and that there should be at least 75000 - 750000 EphA2 receptors per PC-3 cell. However, we found that $\mathbf{Y b}-\mathbf{5 9}$ and Tet-Yb-59 were not completely released from the PC-3 membranes after 20 min at $37^{\circ} \mathrm{C}$ (Fig. 6A and Fig. S11B), indicating that the numbers of initially bound ISErs and the numbers of required EphA2 receptors would need to be higher than 75000 - 750000 per cell.

Jackson et al., 2008 claimed to have detected 16000 EphA2 receptors per PC-3 cells by Scatchard analysis. ${ }^{3}$ If this is true, our PC-3 cells have bound more (Tet-)Yb-59 molecules per cell than receptors available, or alternatively, the activity that is released from (Tet-)Yb-59 incubated PC-3 cells is not caused by intact ISErs or not by ISErs only. Another reason for suspecting that not only dissociated intact ISErs account for the activity released by PC-3 cells at $37^{\circ} \mathrm{C}$, is that the loss of membrane signals of (Tet-) Yb-59 is not occurring faster at $37^{\circ} \mathrm{C}$ than on ice (Fig. 5A, Fig. S11B), which suggests some kind of active (enzymatic or metabolic) process releasing (immune-active) degradation products of ISErs but leaving behind a biotinylated fragment on the cell membranes. One possibility to be pursued is that degradation products formed and released after binding to PC-3 tumor cells include free $\mathrm{N}$-formylated peptides having a much higher potency than the original ISErs.

\section{References}

[1] Rist, R. J., Jones, G. E., and Naftalin, R. J. (1991) Effects of macrophage colony-stimulating factor and phorbol myristate acetate on 2-D-deoxyglucose transport and superoxide production in rat peritoneal macrophages, The Biochemical journal 278 ( Pt 1), 119-128.

[2] Dorward, D. A., Lucas, C. D., Alessandri, A. L., Marwick, J. A., Rossi, F., Dransfield, I., Haslett, C., Dhaliwal, K., and Rossi, A. G. (2013) Technical advance: autofluorescence-based sorting: rapid and nonperturbing isolation of ultrapure neutrophils to determine cytokine production, J Leukoc Biol 94, 193-202.

[3] Jackson, D., Gooya, J., Mao, S., Kinneer, K., Xu, L., Camara, M., Fazenbaker, C., Fleming, R., Swamynathan, S., Meyer, D., Senter, P. D., Gao, C., Wu, H., Kinch, M., Coats, S., Kiener, P. A., and Tice, D. A. (2008) A human antibody-drug conjugate targeting EphA2 inhibits tumor growth in vivo, Cancer Res 68, 9367-9374. 